\title{
A Construção da Indisciplina: um estudo exploratório sobre as possibilidades de compreensão da indisciplina escolar enquanto construção social
}

Isadora Coutinho Moraes ${ }^{1}$

Resumo: O presente artigo tem como objetivo explorar o fenômeno da indisciplina discente enquanto uma construção social que tem origem nas interações que se dão no ambiente escolar. Garcia (2006) afirma que o fenômeno da indisciplina escolar está associado a um modo de produção social de crenças e esquemas de pensamento sobre a escola, o aluno e o professor. Dessa forma, estudar a maneira como os professores pensam a indisciplina pode nos auxiliar a compreender como pensam a escola e seus atores. A partir de entrevistas feitas com um professor do ensino básico sobre indisciplina escolar e, empregando alguns dos pressupostos presentes na abordagem interacionista do fenômeno do desvio desenvolvida por Becker, buscamos analisar como o entrevistado constrói suas crenças sobre a escola e a relação professor-aluno e de que forma tais crenças influenciam a rotulação do comportamento dito "indisciplinado".

Palavras-chave: Indisciplina; Professor; Interacionismo Simbólico

Abstract: This article aims to explore school indiscipline as a social construction which comes from the interactions at the school

\footnotetext{
${ }^{1}$ Graduada em Ciências Sociais pela Universidade Estadual de Maringá (UEM)
} 
environment. Garcia (2006) states that school indiscipline is associated with models of social perception about the school, the student and the teacher. As a result, to study the way teachers thinks about indiscipline could help us understand how they build their conceptions about school and its actors. We try to analyze the way that the teachers build their believes about the school and the teacher-student relations and in which way that influences in the assignment "undisciplined" label on students by interviewing a teacher.

Keywords: Indiscipline; teacher; Symbolic Interactionism

\section{Introdução}

Entre as diversas causas atribuídas ao mau desempenho dos alunos em idade escolar e ao esgotamento dos professores que trabalham com a educação básica, está a indisciplina discente. De acordo com Aquino (2011), o fenômeno surge no Brasil como tema específico de pesquisa a partir dos anos 90, dando origem a diversas publicações na área da Educação, Linguística, História, Serviço Social e Sociologia.

Destacamos, entre os diversos enfoques a partir dos quais o tema da indisciplina escolar tem sido estudado, o recorte privilegiado por autores como Garcia (2009) e Oliveira (2004); isto é, o modo como à indisciplina é pensada pelos professores. Estes estudos investigam a percepção dos docentes sobre as manifestações de indisciplina com as 
quais lidam em seu cotidiano, buscando apreender, assim, a forma como esses profissionais refletem sobre suas práticas em sala. Privilegiaremos, neste artigo, a análise proposta por Garcia (2006), que tem como objetivo investigar como os professores elaboram suas concepções sobre disciplina e indisciplina e como essas concepções refletem crenças sobre a escola e o aluno. Partimos, portanto, da ideia de que os comportamentos considerados como indisciplinados são assim denominados segundo um conjunto de crenças, em função de um modo de leitura socialmente elaborada, uma construção social própria da escola (GARCIA, 2006).

Dessa forma, buscamos explorar a indisciplina escolar enquanto fenômeno que tem origem nas interações sociais que se dão no ambiente escolar, interações estas que incluem desde a definição do que se considera indisciplina até a forma de lidar com suas manifestações. Fazemos, assim, as seguintes perguntas: Qual o conjunto de crenças que orientam a rotulação do comportamento dito indisciplinado? Quais maneiras de "lidar" com este comportamento surgem a partir desta rotulação? Em suma, como o modo de leitura do fenômeno da indisciplina feito pelos professores influencia a forma como esta acontece? Para isso, empregamos a perspectiva interacionista desenvolvida por Becker na obra Outsiders (1963), buscando trazer suas contribuições sobre o fenômeno do desvio para compreensão do fenômeno da indisciplina escolar. 
As reflexões sobre a definição do que é indisciplina, as crenças subjacentes a essa rotulação e o modo de lidar com suas manifestações por parte do docente envolvido com a educação básica, se deram a partir de entrevistas feitas com um professor que leciona a disciplina de Sociologia em três colégios estaduais da cidade de Maringá. As entrevistas, semi-estruturadas, buscaram apreender o que o professor entende por disciplina e indisciplina escolar, como se dão suas manifestações em sala e fora dela, como interage com essas manifestações e quais suas expectativas em relação aos alunos no que se refere à disciplina. As entrevistas foram coletadas durante o período de observação e acompanhamento das aulas para a realização do estágio de licenciatura em Ciências Sociais.

\section{A Noção de "Desvio" em Becker}

Publicada pela primeira vez em 1963, a obra Outsiders, de Howard Becker, inaugurou uma nova forma de olhar para o fenômeno do desvio social. Os estudos publicados sobre o assunto até então encaravam o indivíduo "desviante" - prostitutas, criminosos, delinquentes... -, ora por uma perspectiva de patologia, buscando isolar as características físicas e mentais que os predispunham a cometer atos desviantes, ora por um viés mais sociológico, que concebia o desvio puramente como consequência de disparidades econômicas e sociais. A 
primeira vertente reunia pesquisas que associavam os atos contraventores e antissociais a "falhas de personalidade" ou a determinados traços de comportamentos, como alcoolismo, uso de drogas e má conduta sexual, enquanto a segunda atribuía o surgimento dos "desviantes" à disparidade entre o que lhes haviam ensinado a almejar e sua real possibilidade de alcançar estes prêmios - como no caso dos jovens americanos da classe trabalhadora, que, ao se depararem com a existência de empecilhos socialmente estruturados que os impediam de concretizar os sonhos de mobilidade social, recorriam a métodos desviantes de mobilidade (BECKER, 2008).

Ambas as vertentes excluem de suas análises o processo de julgamento e acusação do indivíduo desviante. Ao buscarem nos próprios indivíduos infratores as "causas" de seu comportamento, estes estudos agem como se o desvio fosse uma característica inerente ao infrator, quando é, na verdade, a consequência da aplicação de uma regra e da punição daqueles que não a seguem. Ignoram, portanto, que os grupos sociais criam o desvio ao criarem as regras que constituem o desvio, ao aplicarem-nas a pessoas particulares e marca-las como outsiders: o desviante é, assim, aquele a quem tal marca foi aplicada com sucesso (BECKER, 2008).

Becker, ao contrário, sugere que a rotulação do comportamento desviante e seus processos de julgamento estão intimamente ligados à própria constituição do fenômeno do desvio (BECKER, 2008). Afinal, 
"tornar-se" um desviante implica ser reconhecido como tal, e este processo de reconhecimento abrange uma série de contingências sociais. O que Becker sugere é que o estudo destas contingências envolvidas na rotulação do comportamento desviante seja incorporado às análises sobre o desvio. Dessa forma, a questão "o que leva determinada categoria de indivíduos a engajarem-se em comportamentos desviantes?" deve ser substituída por: "quais os processos políticos que levam determinado grupo a conseguir impor sua classificação sobre o que deve ser entendido como desvio?", "o que um indivíduo precisa fazer para ser rotulado como desviante?" e, por fim, “quais as consequências dessa rotulação?” (MOURA, 2009). Em suma, deve-se perguntar: quem acusa quem e de quê? (MISKOLCI, 2005).

Para demonstrar que o desvio e a infração não são categorias fixas, "qualitativamente distintas" (BECKER, 2008, P. 17), o autor argumenta que os comportamentos assim denominados variam em cada grupo, e que, da mesma forma que nem todos os indivíduos que cometem atos de infração são assim rotulados, nem todos os que são assim rotulados cometeram, de fato, uma infração. Logo, se a categoria dos "desviantes" carece de homogeneidade e deixa de incluir todos os casos que lhe pertencem, não faz sentido encontrar fatores comuns de personalidade ou situação de vida que justifiquem o suposto desvio (BECKER 2008). 
Dessa forma, ao conceber o fenômeno do desvio como resultado, antes de tudo, da imposição de um rótulo, o autor torna visível a existência de grupos que detém o poder de fazer tal imposição, algo que permanecia oculto nas análises anteriores sobre comportamento desviante. Desnaturaliza, também, os valores segundo os quais essa rotulação é feita. Assim,

"As pesquisas desenvolvidas por autores como Goffman e Becker conseguiram superar o que parecia ser uma conformação dos estudos sociológicos às premissas e, sobretudo, aos objetivos sociais de normalização e controle. A teoria da etiquetagem inaugura uma abordagem em que os comportamentos rotulados como desviantes não são o foco da investigação, antes o meio pelo qual certos grupos sociais detém o poder de rotular outros como desviantes."

(MISKOLCI, 2005, p. 29)

\section{A Construção Social da Indisciplina Escolar}

Vimos que a abordagem interacionista do desvio inaugurada por Becker incorporou o processo de rotulação e julgamento do indivíduo desviante na análise desse fenômeno. Veremos, agora, como esta teoria pode ajudar a pensar o fenômeno da indisciplina escolar. 
Retomando Berger e Luckmann (1991) e seus escritos sobre a construção social da realidade, Garcia (2006) afirma que a interação social nas escolas dá origem a "esquemas de pensamento" sobre a escola, o professor, o aluno e seus respectivos papéis, formas de conduta, identidades, etc. A própria noção de escola é, assim, pensada através de "esquemas de pensamento" que nela se articulam socialmente, e pode ser entendida como fruto de tais esquemas (GARCIA, 2006). Em outras palavras, os indivíduos criam, na interação social que se dá nas escolas, "modos de leitura" sobre a escola e seus sujeitos, e passam a pensá-la e orientar suas ações através de tais esquemas.

Da mesma forma podemos pensar a indisciplina escolar. Se as interações na escola dão origem a crenças sobre a escola, o professor e o aluno, estas crenças são a base para se pensar a indisciplina. É através delas que se define o que se considera indisciplina escolar. Assim,

"as noções de indisciplina, suas expressões e seus sentidos [são] inseparáveis dos nossos esquemas de pensamento sobre o que é a escola, professor, aluno, relação professor-aluno e assim por diante [...] o que os educadores pensam sobre a indisciplina escolar seria inseparável do modo como pensam a escola e a si mesmos".

(GARCIA, 2006, p. 3004) 
O autor propõe, assim, pensar a indisciplina escolar como algo socialmente construído no contexto mais amplo de outras noções socialmente construídas (GARCIA, 2006). Esta abordagem produz uma inversão em relação aos trabalhos que buscam as causas do comportamento indisciplinado nos próprios alunos, e neste sentido, podemos pensar a teoria desenvolvida por Becker como complementar a ela: ao atribuir o fenômeno da indisciplina, entre outros fatores, à construção social de esquemas de pensamento dentro da escola, e sugerir que tais esquemas orientam tanto a definição do que se considera indisciplina quanto o modo de lidar com suas manifestações, a perspectiva apresentada por Garcia desloca o foco dos indivíduos transgressores para o processo através do qual se define $o$ comportamento transgressor. A noção de que os esquemas de pensamento originados nas interações da escola são um dos fatores que dão origem a indisciplina vai ao encontro da ideia que orienta toda a teoria da rotulação desenvolvida por Becker, de que "uma situação dada é o resultado de interações entre os agentes" (MISKOLCI, 2005, p. 47).

Assim, a perspectiva proposta por Garcia sugere a análise do processo de definição do comportamento indisciplinado e das crenças que dão origem a esta definição, tal qual o faz Becker ao propor que o estudo do desvio incorpore a análise do processo de rotulação do comportamento desviante, ao invés de se concentrar nos motivos que 
levam determinados indivíduos a engajarem-se em atividades desviantes.

Dessa forma, ainda que o sistema de valores e crenças que os professores possuem sobre a escola e seus sujeitos não sejam os únicos elementos que produzem a indisciplina - que existe não só como criação daqueles envolvidos no cotidiano escolar - este sistema de crenças possui um importante papel na criação social do fenômeno. Para além da investigação das causas que levam ao comportamento indisciplinado, é preciso investigar o processo de construção da noção de indisciplina - isto é, quais os esquemas de pensamento que dão origem a esta noção?

Para Garcia, este conjunto de esquemas de pensamento deve ser investigado também em suas implicações (GARCIA, 2009). Isto por que:

"O modo como a indisciplina está sendo pensada entre professores pode nos auxiliar a compreender suas ações. [...] Como bem observou Lenoir (1998, p. 48), as representações dos professores nos informam sobre como pensam suas práticas, além de exercer um papel importante na orientação de suas ações."

(GARCIA, 2009, p. 315).

Em outras palavras, deve-se investigar como suas crenças sobre indisciplina influenciam a forma como organiza seu trabalho em sala. 
Tendo em vista, portanto, a possibilidade de investigar como a interação social nas escolas dá origem às crenças sobre a indisciplina, e como os esquemas através dos quais a indisciplina é pensada exercem um papel importante na construção social desse fenômeno, procuramos analisar as crenças de um professor de ensino médio sobre a indisciplina escolar, buscando responder às seguintes perguntas: o que o professor entende por indisciplina? Quais crenças sobre escola, aluno e professor se revelam em seu discurso ao falar sobre indisciplina? Essas crenças influenciam a forma como organiza seu trabalho em sala?

Cabe lembrar que nosso objetivo não é realizar uma análise interacionista do fenômeno da indisciplina escolar, investigando pormenorizadamente as etapas que levam alguns indivíduos a receberem o rótulo de "desviantes", mas sim direcionar o foco de nossa investigação para as crenças em torno das quais tem origem a rotulação do comportamento "indisciplinado".

O professor entrevistado, contratado em regime temporário por meio do Processo Seletivo Simplificado (PSS), leciona a disciplina de Sociologia em três colégios da rede estadual de ensino do Paraná desde 2006. As entrevistas, semi-estruturadas, foram coletadas durante o período de observação das aulas para a realização do estágio de licenciatura em Ciências Sociais.

Ao ser questionado sobre suas expectativas em relação aos alunos no que se refere à disciplina em sala de aula, o professor 
destacou, como comportamentos desejados, a ausência de conversas paralelas com os colegas durante as explicações e as "demonstrações de interesse" na aula (perguntas e comentários feitos para o professor sobre o tema que está sendo trabalhado). Em contrapartida, os comportamentos indesejados seriam as conversas paralelas durante a aula (apontada como um tipo de indisciplina "mais inocente" (entrev.)) e a apatia, o desinteresse, que se traduzem na recusa em realizar as atividades propostas (destacada como um tipo de indisciplina "mais problemática" (entrev.), mais difícil de lidar). Essa afirmação vem acompanhada da ressalva de que estar na condição de aluno é algo que naturalmente dificulta o comportamento desejado:

"Só que na verdade, todos nós almejamos interação [...] quando o professor troca de cadeira com o aluno, o professor se transforma em aluno, parece que quando você se coloca na condição de aluno seu comportamento muda [...]. Aluno é aluno." (Entrevista professor)

O professor cita como exemplo as reuniões pedagógicas do colégio, nas quais os professores têm dificuldade de ficar em silêncio e precisam ser constantemente "chamados a atenção". Isto por que:

"a indisciplina ela está no processo de aprendizagem, porque é muito difícil domar os nossos comportamentos, é claro que a gente tem que 
tentar ser cada vez mais disciplinado [...], mas a indisciplina existe e ela sempre vai existir."

(Entrevista professor)

A indisciplina discente é aqui entendida, portanto, como algo inerente ao processo de aprendizagem, que pode ser "controlada" momentaneamente, mas que nunca estaria completamente ausente do contexto da sala de aula por fazer parte da relação professor-aluno. $\mathrm{O}$ aluno, nesta perspectiva, não se distingue como o único responsável pelos contextos de indisciplina, mas é um ator social cujo papel se desdobra na relação com outros atores sociais (GARCIA, 2009).

Esta perspectiva também se afasta da concepção de indisciplina como uma "definição negativa" de escola, como um elemento incompatível com o bom andamento do projeto de escola (GARCIA, 2006). Ao invés de pensar escola e indisciplina como "realidades mutuamente excludentes" (GARCIA, 2006, p. 3004), esta última é entendida como um elemento que faz parte da relação ensinoaprendizagem.

A construção do aluno enquanto ser que "almeja interação" possibilita o entendimento das conversas paralelas entre as explicações como comportamento natural e até mesmo previsível, ao mesmo tempo em que faz da apatia e da recusa em comparecer às aulas e realizar as atividades propostas, comportamentos ditos "problemáticos". Assim, a partir da construção de uma determinada noção de "aluno", atribui-se 
diferentes sentidos à indisciplina escolar - a indisciplina "mais inocente" e a "mais problemática".

A partir desse modo de leitura do aluno, da relação professoraluno e da indisciplina escolar, elabora-se também um modo particular de se organizar o trabalho em sala. Uma vez que a indisciplina discente é entendida como algo que faz parte do processo de aprendizagem e da relação professor-aluno, e não como uma característica de alguns alunos ou como consequência de elementos que vêm de fora da escola, o caminho proposto para "lidar" com sua presença em sala passa pela modificação da relação entre professor-aluno. Dessa forma, o professor destaca algumas estratégias práticas que emprega para tornar o exercício de "ficar quatro horas sentado" (entrev.) atento à aula exercício que entende como algo naturalmente "difícil" - "mais dinâmico e menos monótono" (entrev.):

"Mas é claro que a gente tem que encontrar um caminho pra colocar o aluno pra aprender, porque agora ele não percebe [...] mas isso é importante. [...] A resposta pra isso é um pouco [procurar ter] dinâmica [...], tentar andar bastante pela sala, tentar tornar o assunto agradável, tenta tornar a aula menos monótona possível."

(Entrevista professor)

Outra estratégia para modificar a dinâmica das aulas é a adoção de um sistema de concessão de notas aos alunos que se dispõe a 
comentar ou a responder um dos exercícios propostos, no momento da correção destes. Este sistema foi aplicado em várias das aulas que acompanhamos, e pode ser interpretado como uma forma de garantir maior participação dos alunos, tornando as aulas "mais dinâmicas", e diminuindo a tendência ao "tipo" de indisciplina que considera "mais problemática", ou seja, a apatia e o desinteresse em relação ao conteúdo ministrado e às atividades propostas.

Dessa forma, pode-se observar que a noção de "aluno" ajuda a entender como o professor pensa a indisciplina escolar, a relação professor-aluno e suas práticas em sala. A partir da construção de determinados esquemas de pensamento que se articulam no ambiente escolar, têm origem as definições de "indisciplina".

\section{Considerações Finais}

Neste artigo, buscamos desenvolver a noção de indisciplina escolar enquanto rótulo que tem origem a partir de um modo de leitura socialmente construído sobre a escola, o aluno e o professor. Pensar o processo de definição do comportamento considerado "indisciplinado" através dos esquemas de pensamento que são elaborados nas interações dentro das escolas pode nos auxiliar a compreender o papel dos professores e dos demais profissionais que atuam nesta instituição na construção social da indisciplina discente. Neste sentido, a análise 
interacionista do desvio realizada por Becker pode ser pensada como uma contribuição para a análise do fenômeno da indisciplina escolar: da mesma forma que o autor desloca o foco das investigações sobre as características psicológicas, traços de comportamentos ou condicionantes econômicos que os indivíduos compreendidos na categoria de "desviantes" teriam em comum, passando a analisar o processo de rotulação destes indivíduos como desviantes, a indisciplina pode deixar de ser pensada somente como resultado de certas características dos alunos "indisciplinados".

Esta perspectiva auxilia na desconstrução da idéia de passividade dos professores diante dos quadros de indisciplina, ao sugerir que lidar com sua presença no contexto escolar exige repensar visões e posições em relação ao projeto pedagógico, ao modo de funcionamento e à cultura da escola (GARCIA, 2009). Dessa forma, ao invés de reforçar uma retórica de culpabilização e isolamento daqueles alunos que são identificados como pertencentes à categoria dos "indisciplinados", a interação e a busca por "soluções" para os problemas de indisciplina exige a leitura da cultura institucional da escola (GARCIA, 2009).

Buscamos, por fim, exemplificar uma das possibilidades de utilização da noção de indisciplina escolar enquanto construção social para se compreender o modo como os professores pensam suas práticas profissionais, através da entrevista com o professor de Sociologia. A 
partir da entrevista, pudemos perceber que a forma como o professor constrói sua noção de "aluno" influencia o modo como percebe a indisciplina, atribuindo dois diferentes sentidos a ela. Através deste modo de leitura da indisciplina, do aluno e da relação entre professor e aluno, elaboram-se modos distintos de lidar com suas manifestações, como exemplifica o professor ao descrever o modo como organiza seu trabalho em sala.

\section{Bibliografia}

AQUINO, Julio Groppa. (2011) Da (contra)normatividade do cotidiano escolar: problematizando discursos sobre a indisciplina discente. Cadernos de Pesquisa, São Paulo, v. 41, n. 143, p.456-484, maio/ago. 2011. Quadrimestral.

BECKER, Howard. (2008). Outsiders: Estudos de Sociologia do Desvio. Rio de Janeiro: Zahar.

BERGER, Peter; LUCKMANN, Thomas. (1994). A construção Social da Realidade: tratado de sociologia conhecimento. 11. ed. Petrópolis: Vozes.

GARCIA, Joe. (2006). A Construção da Indisciplina na Escola. In: VI Congresso Nacional de Educação da PUCPR - EDUCERE, 2006, Curitiba. Anais... Curitiba: Champagnat. v. 1. p. 3001-3008. 
GARCIA, Joe. (2009). Representações dos Professores sobre Indisciplina Escolar. Educação, Santa Maria, v. 34, n. 2, p.311-324, maio 2009.

MISKOLCI, Richard. (2005). Do Desvio às Diferenças. Teoria \& Pesquisa: Revista de Ciência Política, São Carlos, v. 47, n. 1, p.9-42, jul. 2005. Semestral.

MOURA, Cristina Patriota de. (2009). Outsiders: estudos de sociologia do desvio. Mana, Rio de Janeiro, v. 15, n. 2, Oct. 2009. Quadrimestral. 